\title{
INVESTIGATION ON THE POST-PROCESSING OF BLAST LOADING CHARACTERISTICS ALONG A CONVEX STRUCTURE
}

\author{
MICHEL-OLIVIER STURTZER ${ }^{1}$, SOPHIE TRÉLAT ${ }^{2}$ \& LAURENT SINNIGER $^{1}$ \\ ${ }^{1}$ ISL, French-German Research Institute of Saint-Louis, France \\ ${ }^{2}$ IRSN, Institut de Radioprotection et de Sûreté Nucléaire, France
}

\begin{abstract}
Interaction between large blast and targets can rarely be studied directly, due to cost and practicality considerations. Blast tests using reduced-scale high explosive charges represent an attractive alternative. The first necessary step consists in studying blast propagation in free-field at the considered reduced-scales. The second step focuses on the determination of the blast load around various types of reference obstacles, in order to provide a critical input for numerical simulation. This approach also aims to build simplified models allowing faster risk assessment processes for government agencies. Since 2017, the French Institute for Radiological Protection and Nuclear Safety (IRSN) and the FrenchGerman Research Institute of Saint-Louis (ISL) have been studying blast propagation in free-field and in front of a hemi-cylinder at two different reduced scales using Hexomax ${ }^{\circledR}$ charges. IRSN developed a significant experience on hemispherical blast effect assessment using $42 \mathrm{~g}$ reference Hexomax ${ }^{\circledR}$ charges detonated in contact to a planar surface supporting a hemi-cylindrical obstacle, both equipped with pressure sensors including two types of technologies: piezo-electric and piezo-resistive. Based on this experience, ISL developed its own outdoor blastpad: 333 g Hexomax ${ }^{\circledR}$ charges are detonated in a factor two up-scaled version of the IRSN test configuration. Similar sensors are flush-mounted on the pad and the surface of an up-scaled version of the IRSN obstacle. To assess the resulting experiments extensibility, blast characteristics were measured at distances ranging between 0.6 and $3.5 \mathrm{~m} / \mathrm{kg}^{1 / 3}$ from the different charges with or without obstacle. A classic post-processing methodology identified in the literature was applied to determine all peak overpressure values. The results were consequently compared to the directly determined values in order to propose a unified technique of processing overpressure data for reduced-scale blast tests, including various types of pressure sensors. Finally, this work contributes to the optimization of large scale blast tests designed to evaluate structural response. Keywords: blast wave, hemi-cylindrical structure, detonation, plastic explosives, reduced-scale charges, effects on infrastructures, experiments, convex, pressure gauges.
\end{abstract}

\section{INTRODUCTION}

The Institute for Radiological Protection and Nuclear Safety (IRSN) is a French public institute with industrial and commercial activities, placed under the joint authorities of the Ministries of Defense, Environment, Industry, Research, and Health. IRSN is entrusted, among others, to assess and conduct researches in the area of the protection of nuclear facilities and transport of radioactive and fissile materials against accidental and malicious acts. In this context, IRSN establishes projects and studies to improve its knowledge of blast characteristics and weapons effects.

The French-German Research Institute of Saint-Louis (ISL) is a bi-national research institute established by the Federal Republic of Germany and the French Republic on the basis of a treaty signed in 1958. The core mission of ISL is: "Research, scientific studies and basic predevelopment in the field of defense and security". Among other tasks, ISL focuses on the physical protection of personnel and assets against the effects of various types of explosive charges. To improve general survivability, fundamental studies on blast wave propagation and target interaction are continuously being conducted at ISL. 
In 2006, IRSN designed and built an experimental set-up to achieve non-destructive shock wave propagation studies on a small scale [1], [2]. This set-up is composed of a modular table, sensors and targets able to perform the detonation of solid explosives up to $64 \mathrm{~g}$ of TNT equivalent, representing an alternative to the gas mixture detonation propagation configuration for small-scale tests [3], [4]. Blast generated by $50 \mathrm{~g}$ TNT equivalent hemispherical Hexomax ${ }^{\circledR}$ charges was consequently characterized. To evaluate the effect of scale, a joint study between IRSN and ISL was initiated in 2017, based on a dedicated ISL blast pad replicating the IRSN table at a double scale: $400 \mathrm{~g}$ TNT equivalent hemispherical Hexomax ${ }^{\circledR}$ charges are being investigated.

One objective of these studies, described in this paper, is to provide an overview of the extensibility of reduced-scale blast propagation experiments using high explosive charges as well as guidelines for the use of the different types of pressure gauges commonly used for blast wave studies.

\section{EXPERIMENTAL SETUP}

\subsection{IRSN setup}

The IRSN blast table has been principally designed to study shock waves reflection phenomena and interaction with different non-deformable structures. It measures $1.6 \times 2.4$ meters and features an array of mounting holes that facilitates the placement of modular 0.4 x $0.4 \times 0.05 \mathrm{~m}$ wooden plates and pressure transducers (Fig. 1). For this campaign, different types of pressure transducers (piezo-electric and piezo-resistive) separated by $133 \mathrm{~mm}$ are mounted on an elastic support and their signals are recorded at $500 \mathrm{kHz}$ by a Nicolet Genesis data acquisition system. Explosive charges are installed and ignited on a dedicated reinforced steel table plate to generate a hemispherical blast wave using a Davey-Bickford SA 4201A detonator. Experimental campaigns were performed at the ArianeGroup's research center located near Paris (Vert-le-Petit, France).

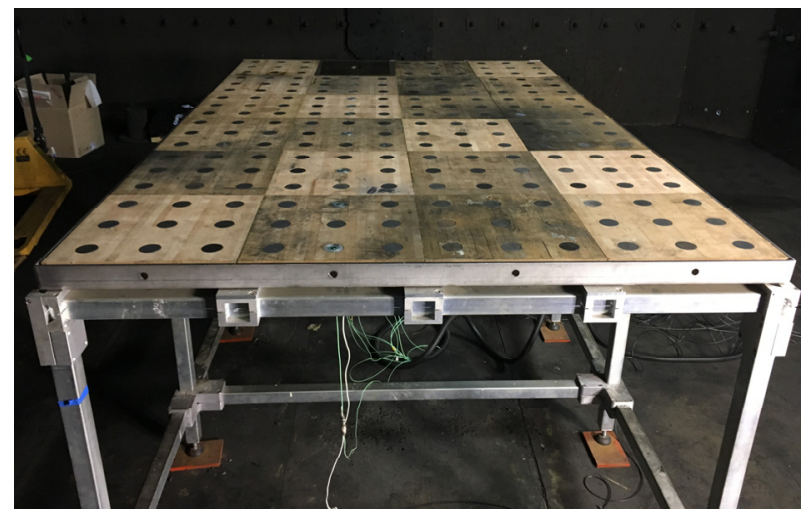

Figure 1: IRSN blast table.

A wooden hemi-cylindrical structure can be fixed on the table surface. The $0.4 \mathrm{~m}$ diameter hemi-cylinder has the same length $(1.6 \mathrm{~m})$ as the table in order to avoid lateral bypass of the shock wave (see Fig. 2). The target is sufficiently rigid to withstand repeated blast loading without damage or deformation. Five pressure gauges separated by $30^{\circ}$ can be installed on 


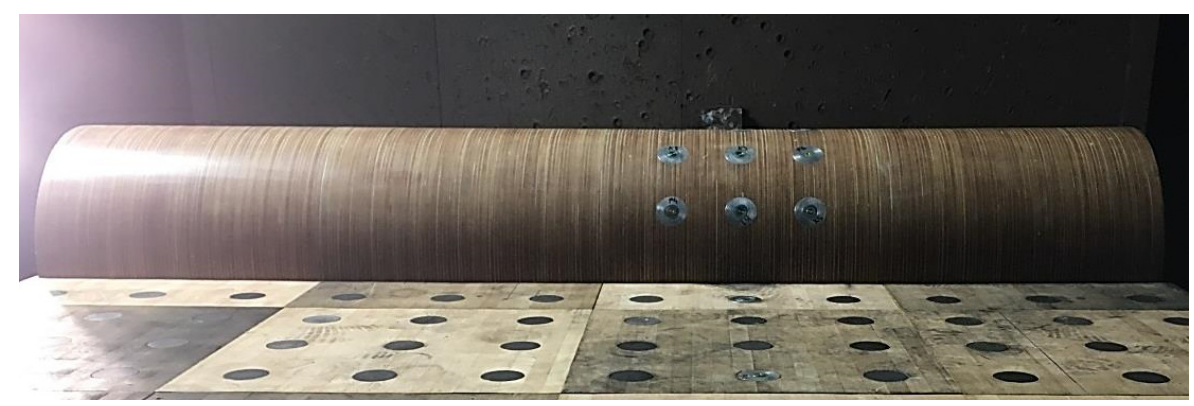

Figure 2: View of the wooden hemi-cylinder lying on the table with holes for sensor positioning.

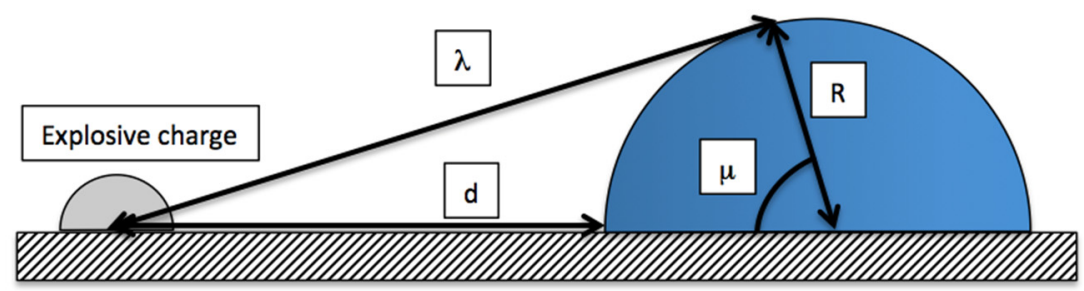

Figure 3: Schematic of the hemi-cylindrical obstacle configuration.

the target surface along three vertical lines facing the explosive charge. Geometrical characteristics of the complete setup are presented in Fig. 3.

\subsection{ISL setup}

ISL developed a dedicated outdoor blast pad (Fig. 4 (left)): explosive charges are detonated in a factor 2 up-scaled version of IRSN test configuration. Each explosive charge was installed on a dedicated reinforced steel ground plate to generate a hemispherical blast wave. Based on IRSN previous work, ISL also designed a factor two upscaled (shorter) hemicylindrical target (Fig. 4 (right)) that can be mounted on the blast pad surface: $0.8 \mathrm{~m}$ diameter and $0.8 \mathrm{~m}$ long with five lines of instrumentation ports. For this campaign, different types of pressure transducers were mounted on polypropylene supports inserted in the integrated rail or the hemi-cylinder ports, each respectively separated by $266 \mathrm{~mm}$ or $30^{\circ}$. All data were recorded using a Transcom system running at $2 \mathrm{MHz}$.

\subsection{Pressure sensors positions}

All distances presented in the rest of this document correspond to IRSN scale. ISL distances and times have all been downscaled for direct comparison. Table 1 presents the position of all sensors for free-field tests at both scales (reduced distances ranging between 0.57 and $4.6 \mathrm{~m} / \mathrm{kg}^{1 / 3}$ for a TNT equivalent spherical charge). Depending on the measured overpressure range, different sensors were installed: Kulite XT190 or HKS375, PCB M102A, M102A6 or 113B28, Kistler 603B and PCB 113B28. 

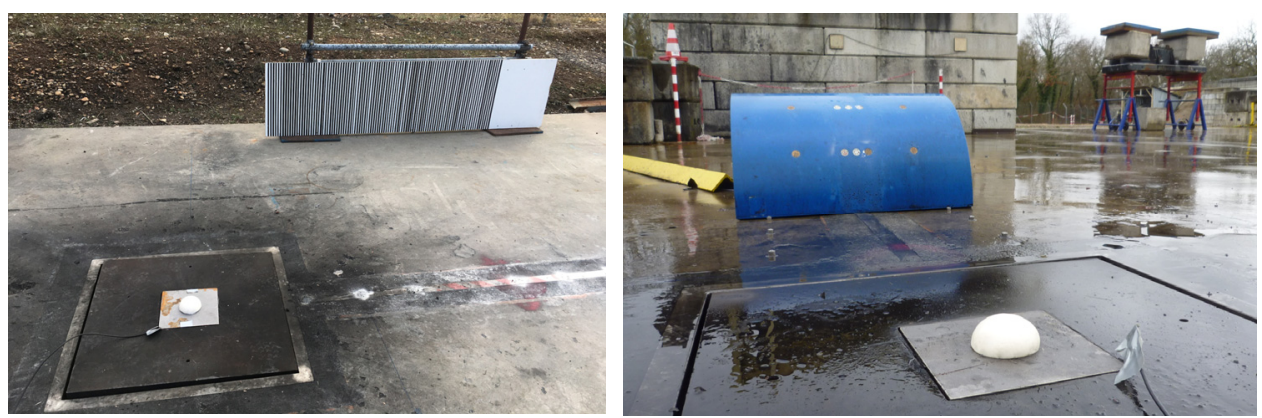

Figure 4: ISL Blast pad and hemi-cylindrical obstacle.

Table 1: Free-field metrology specifications.

\begin{tabular}{|c|c|c|c|c|}
\hline Distance $(\mathrm{m})$ & ISL PCB & ISL Kulite & IRSN Kistler & IRSN Kulite \\
\hline 0.267 & $\mathrm{x}$ & $\mathrm{x}$ & $\mathrm{x}$ & $\mathrm{x}$ \\
\hline 0.400 & $\mathrm{x}$ & $\mathrm{x}$ & $\mathrm{x}$ & $\mathrm{x}$ \\
\hline 0.533 & $\mathrm{x}$ & $\mathrm{x}$ & $\mathrm{x}$ & $\mathrm{x}$ \\
\hline 0.667 & & & $\mathrm{x}$ & $\mathrm{x}$ \\
\hline 0.800 & $\mathrm{x}$ & $\mathrm{x}$ & & $\mathrm{x}$ \\
\hline 0.933 & $\mathrm{x}$ & $\mathrm{x}$ & $\mathrm{x}$ & \\
\hline 1.067 & $\mathrm{x}$ & $\mathrm{x}$ & & $\mathrm{x}$ \\
\hline 1.200 & $\mathrm{x}$ & & $\mathrm{x}$ & \\
\hline 1.867 & $\mathrm{x}$ & $\mathrm{x}$ & & $\mathrm{x}$ \\
\hline 2.000 & $\mathrm{x}$ & & & \\
\hline 2.133 & $\mathrm{x}$ & & $\mathrm{x}$ & \\
\hline 3.066 & $\mathrm{x}$ & & & \\
\hline
\end{tabular}

Hemi-cylinder ports at 30 and $60^{\circ}$ of elevation were equipped with Kistler (IRSN), PCB (ISL) and Kulite (ISL) sensors, as described in Table 2. Further angular positions pressure recordings are analysed in [5]: the wave propagating at $90^{\circ}$ and above is strongly influenced by the expansion around the hemi-cylinder [4]-[6]. At 30 and $60^{\circ}$, as the flow is being compressed on the front face of the obstacle, shockwave type profiles (steep increase) are still being recorded.

Table 2: Hemi-cylinder metrology specifications.

\begin{tabular}{|l|c|c|c|}
\hline Angle & ISL PCB & ISL Kulite & IRSN Kistler \\
\hline $30^{\circ}$ & $\mathrm{x}$ & $\mathrm{x}$ & $\mathrm{x}$ \\
\hline $60^{\circ}$ & $\mathrm{x}$ & $\mathrm{x}$ & $\mathrm{x}$ \\
\hline Lateral offset $(\mathrm{mm})$ & 0 & 25 & 0 \\
\hline $\mathrm{d}(\mathrm{m})$ & $0.266 / 0.4 / 0.6 / 1 / 1.6$ & $0.4 / 0.6 / 1.6$ \\
\hline
\end{tabular}


Results presented in this document were recorded for five different values of the d distance (charge to hemi-cylinder, Table 2): 0.266, 0.4, 0.6, 1 and $1.6 \mathrm{~m}$.

\subsection{Explosive charges}

The explosive charges consisted of Hexomax ${ }^{\circledR}$ hemispheres, initiated from the bottom using an electrical detonator (Davey-Bickford SA-4201 at IRSN or RP83 at ISL). For these tests, the considered masses were $41.6 \mathrm{~g}$ (IRSN) and $333 \mathrm{~g}$ (ISL) of Hexomax ${ }^{\circledR}$ (50 and $400 \mathrm{~g}$ in TNT pressure equivalent). Each charge was placed directly either on the table or the blast surface (see Fig. 5). Charges characteristics are reported in Table 3.
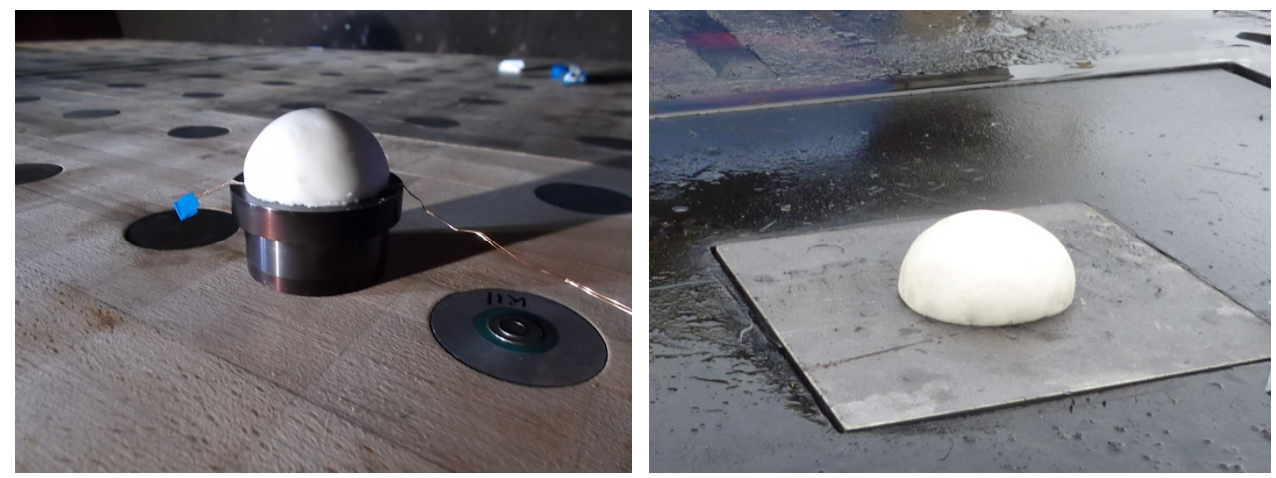

Figure 5: Hexomax ${ }^{\circledR}$ charges. Left: IRSN; Right: ISL.

Table 3: Explosive charges characteristics.

\begin{tabular}{|l|c|c|}
\hline Configuration & IRSN & ISL \\
\hline Mass $(\mathrm{g})$ & 41.6 & 333 \\
\hline Diameter $(\mathrm{mm})$ & 46.6 & 94 \\
\hline Density $\left(\mathrm{g} / \mathrm{cm}^{3}\right)$ & 1.58 & 1.54 \\
\hline Igniter & SA-4201 & RP83 \\
\hline Pressure TNT eq. $(\mathrm{g})$ & 50 & 400 \\
\hline
\end{tabular}

\subsection{Post-processing method}

An example of overpressure evolution is presented in Fig. 6: side-on overpressure recorded at $3.74 \mathrm{~m}$ from a $333 \mathrm{~g} \mathrm{Hexomax}{ }^{\circledR}$ charge at ISL scale. Both signals were shifted to a time of arrival of $0 \mathrm{~s}$. Direct determination of peak overpressure leads to 2.46 and 1.9 bar respectively for the PCB and the Kulite gauges. This type of signal can however also be processed using the method described in literature [7], [8]. This technique (referred to as KG) proved to be efficient in discarding non-physical artefacts transmitted by pressure sensors or reduce the response discrepancy between sensor types as it can be observed in Fig. 6: peak overpressure values obtained by post-processing are 1.85 bar for the PCB sensor and 2.05 bar for the Kulite. The fast-responding piezo-electric (PE) sensor initial overshoot and the longer rise time piezo-resistive (PR) sensor are partially compensated by this method, providing a reduced difference between the two peak values. 

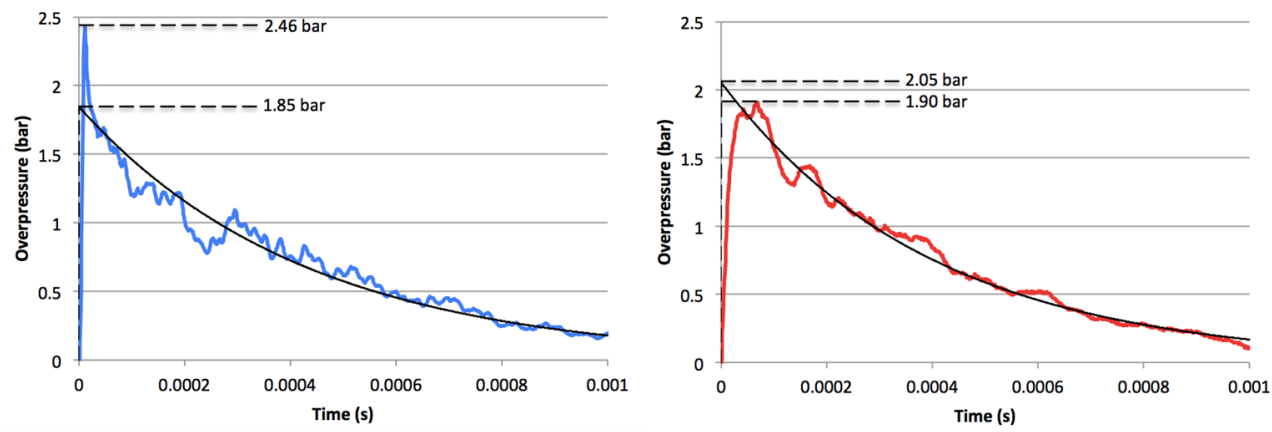

Figure 6: Free-field overpressure evolutions (PCB on left, Kulite on right) at $3.74 \mathrm{~m}$ from a 333 g Hexomax ${ }^{\circledR}$ charge - direct versus post-processed (KG) peaks.

\section{FREE-FIELD RESULTS AND ANALYSIS}

\subsection{Overpressure measurements}

Fig. 7 represents all Kulite sensors peak overpressure values versus scaled distance for IRSN and ISL tests, through direct and processed determination. As mentioned previously, KG processed data appear to be higher than direct determined values as piezo-resistive Kulite gauges tend to underestimate the dynamic pressure rise due to the shock wave passage.
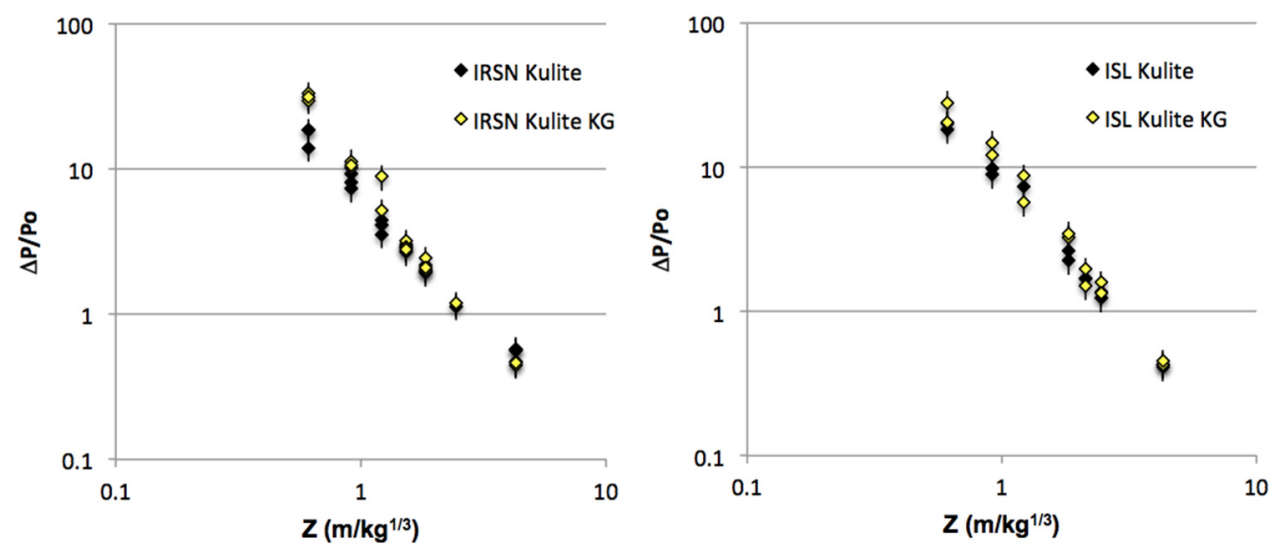

Figure 7: Peak overpressure evolution for Kulite sensors (IRSN and ISL).

Fig. 8 illustrates the same overpressure versus scaled distance evolutions for piezo-electric gauges: Kistler at IRSN scale and PCB at ISL scale. KG processing seems to moderate the direct determined values of peak overpressures, mostly through initial overshoot compensation but also few underestimations especially in close range (non-ideal shock structure generated by the proximity to the explosive charge leading to an initial complex pressure evolution). 

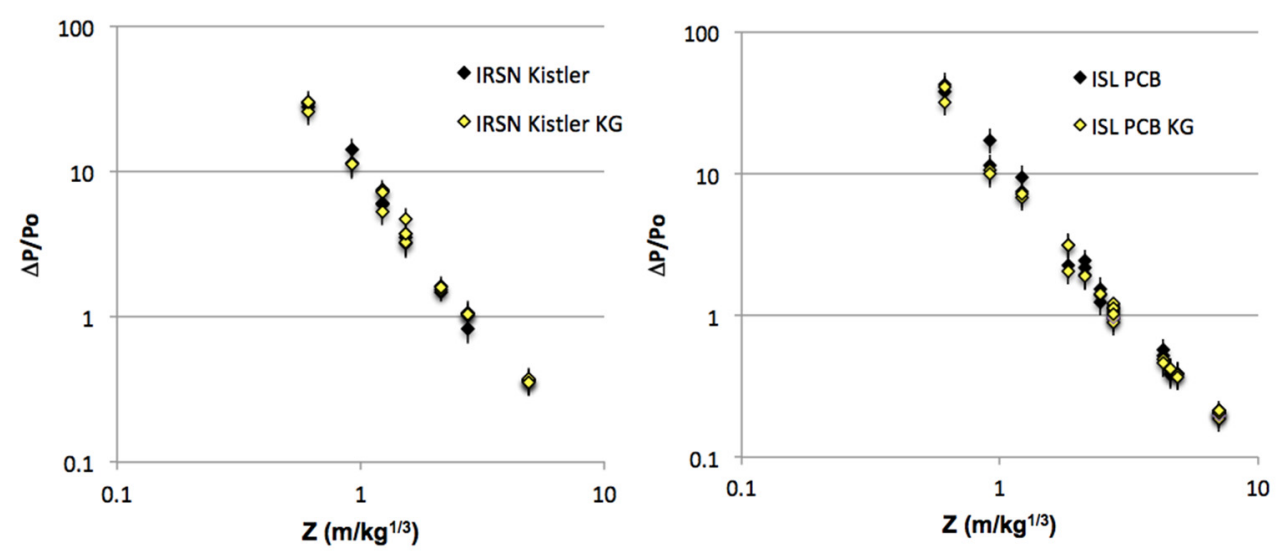

Figure 8: Peak overpressure evolution for Kistler (IRSN) and PCB (ISL) sensors.

\subsection{Interscale comparison}

Peak overpressures versus scaled distance are compared in Fig. 9 for piezo-electric (Kistler at IRSN, PCB at ISL) and piezo-resistive (Kulite at IRSN and ISL). Each point corresponds to the average of all measurements realised in the same conditions (sensor, scale and distance). These results are compared to the side-on overpressure evolution predicted by Kinney and Graham [7].

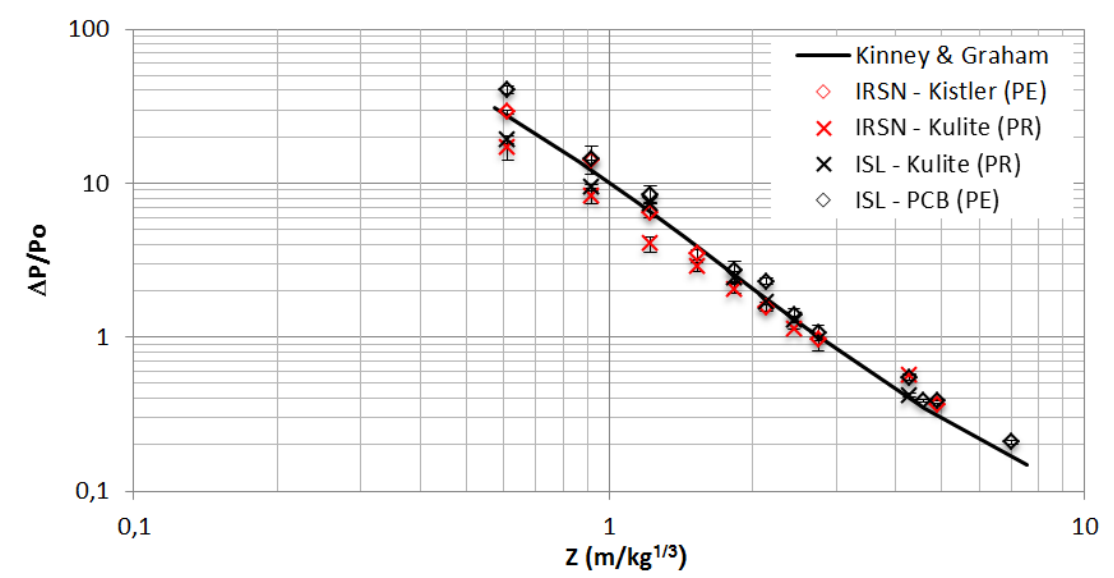

Figure 9: Average peak overpressure versus scaled distance for both scales and all types of sensors.

In close range, piezo-resistive sensors recorded average peak overpressure values $40 \%$ lower than piezo-electric sensors, at both test scales. This difference progressively decreases with the scaled distance. Convergence between the different sensor types responses is observed at an average scaled distance of $2 \mathrm{~m} / \mathrm{kg}^{1 / 3}$ (1.5 for IRSN, 2.3 for ISL). This observation can be explained by three phenomena: 
- Fireball proximity: thermal radiation during the charge explosion influences nearby sensors (gain alteration). Piezo-electric gauges are especially sensitive to this thermal transfer;

- Distance to the charge: the closer the pressure gauge, the higher the overpressure values leading to a probable oscillation due to the mechanical sensitivity of the piezo gauges [9]. Signal filtering may not be sufficient to address this issue, especially for the piezoelectric sensors (Kistler and PCB);

- Rise time differences: despite the lack of available and precise data acquired in a controlled environment, it is generally assumed that piezo-resistive sensors tend to present slower rise time than piezo-electric sensors for a similar pressure sensitivity.

\subsection{Results dispersion}

Fig. 10 summarizes all peak overpressure measurements at both scales and for all sensors on the left for the direct and on the right for the KG processed methods. KG significantly decreases the global dispersion of peak pressure measurements especially below $2 \mathrm{~m} / \mathrm{kg}^{1 / 3}$. The precise determination of the KG processing effect on the dispersion will require a dedicated dataset including a similar number of peak overpressure values per sensor type and position.
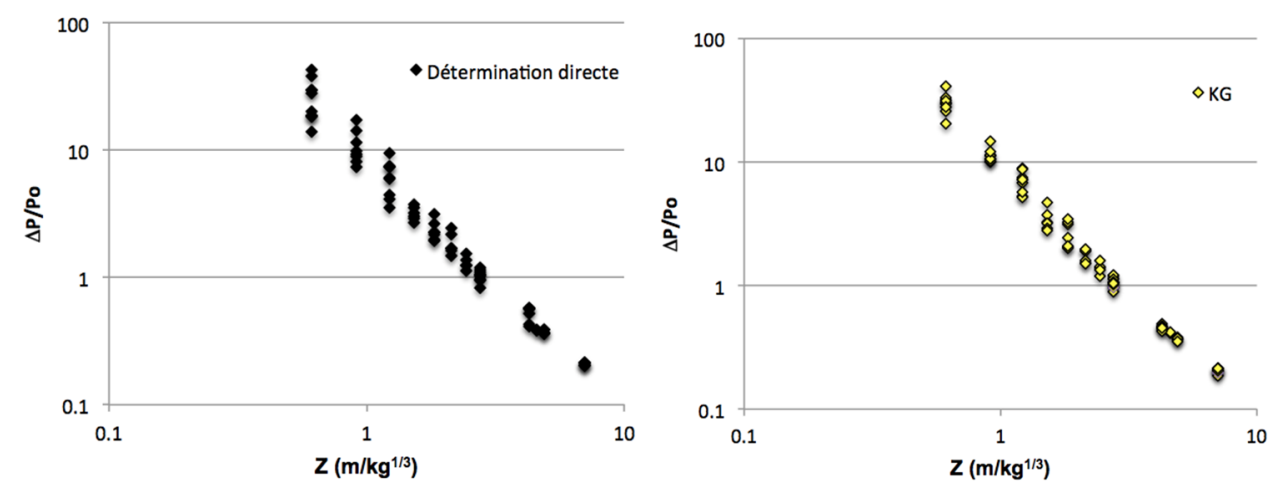

Figure 10: Results dispersion for direct and KG methods.

\section{HEMI-CYLINDER RESULTS AND ANALYSIS}

\subsection{Overpressure measurements}

Overpressure evolutions versus time for all sensors on the ISL hemi-cylindrical obstacle at $3.2 \mathrm{~m}$ (ISL scale) are presented in Fig. 11 in order to illustrate the different types of signal recorded [5]: on the front face $\left(30\right.$ and $\left.60^{\circ}\right)$, the shock wave is being strengthened by the progressive compression consequent to the interaction with the obstacle. The pressure decay is consequently modified in comparison with the free-field classic profile [7], preventing the direct application of the KG processing method. At further angular positions (90, 120 and $150^{\circ}$ ), the expansion around the hemi-cylinder mitigates the intensity of the inbound shock, leading to a more progressive pressure increase, as the wave slows down towards a sonic velocity [3]. 


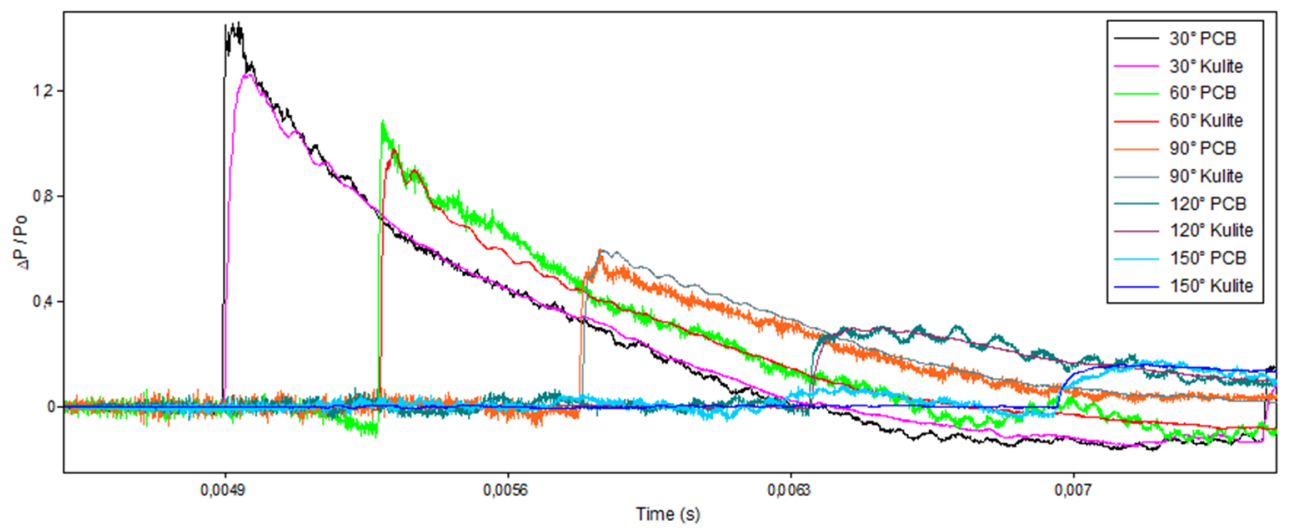

Figure 11: Overpressure evolution on ISL hemi-cylinder surface $(\mathrm{d}=3.2 \mathrm{~m}-\mathrm{ISL}$ scale).

\subsection{Interscale comparison}

Peak overpressures recorded at 30 and $60^{\circ}$ hemi-cylinder positions versus $\mathrm{d} / \mathrm{R}$ ratios are compared in Fig. 12 for piezo-electric (Kistler at IRSN, PCB at ISL) and piezo-resistive (Kulite at ISL). Each point corresponds to the average of all measurements realised in the same conditions (sensor, scale and angular position). Peak overpressures recorded by piezoelectric sensors (Kistler and PCB) are in good agreement between the two scales. As for freefield, measurements for low $\mathrm{d} / \mathrm{R}$ (close range) demonstrate a significant difference between piezo-electric and piezo-resistive peak overpressure. Fig. 13 illustrates the discrepancy of the piezo-resistive in comparison to the piezo-electric sensors for all measurements versus the dimensionless distance from the charge to the obstacle $\mathrm{d} / \mathrm{R}$ ratio. Values range from above $60 \%$ down to $25 \%$ at $30^{\circ}$ and from $50 \%$ down to $15 \%$ at $60^{\circ}$.
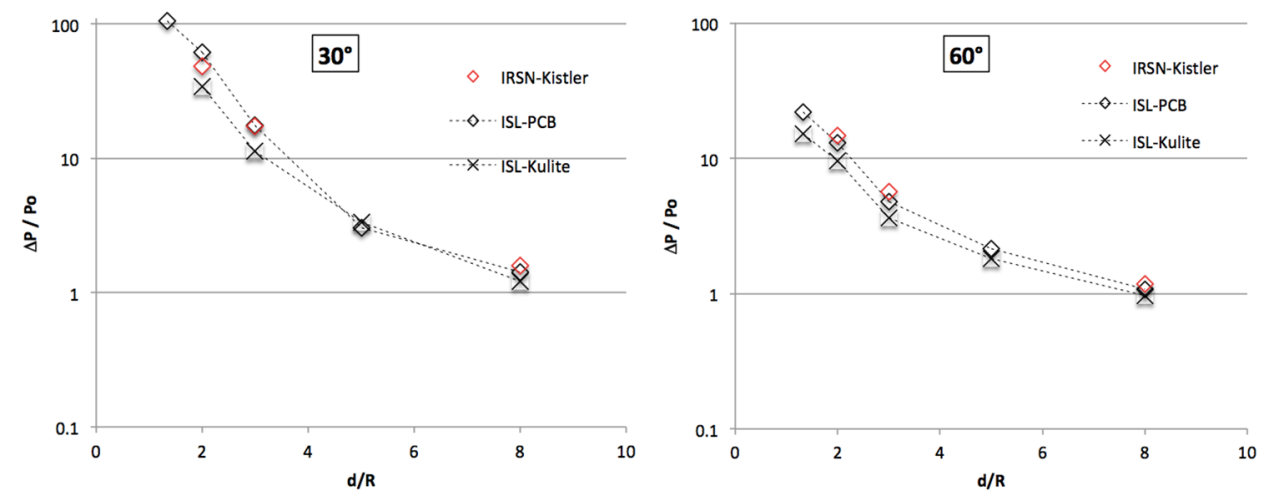

Figure 12: Average peak overpressure at 30 and $60^{\circ}$ at both scales and for Kistler, Kulite and PCB sensors. 


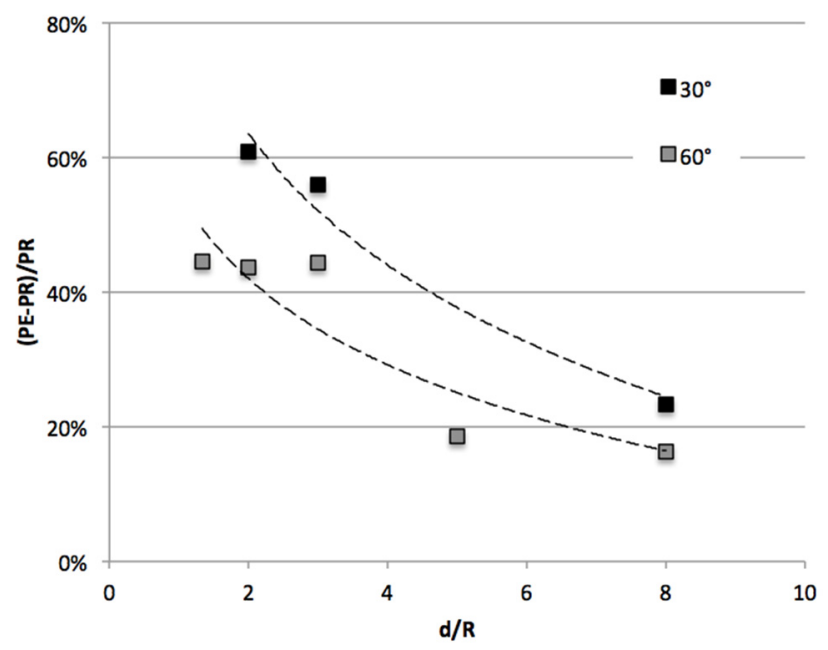

Figure 13: Average peak overpressure discrepancy between piezo-electric (PE) and piezoresistive (PR) sensors at 30 and $60^{\circ}$ position for both scales.

\subsection{Results dispersion}

Fig. 14 summarizes all peak overpressure measurements at both scales and for all PE and PR sensors at 30 and $60^{\circ}$ angular positions on the hemi-cylinder. Close-in measurements $(d / R<5)$ with high overpressure values exhibit significantly higher dispersion of results in comparison to further distances, in a similar way observed previously with free-field tests. For example, Fig. 15 illustrates the discrepancy between a small scale (IRSN) Kistler record and a double scale (ISL) Kulite record. A future adapted processing treatment based on KG method could partially decrease this close range phenomenon influence, as other factors (scale, fireball, soil material, etc.) are also responsible.
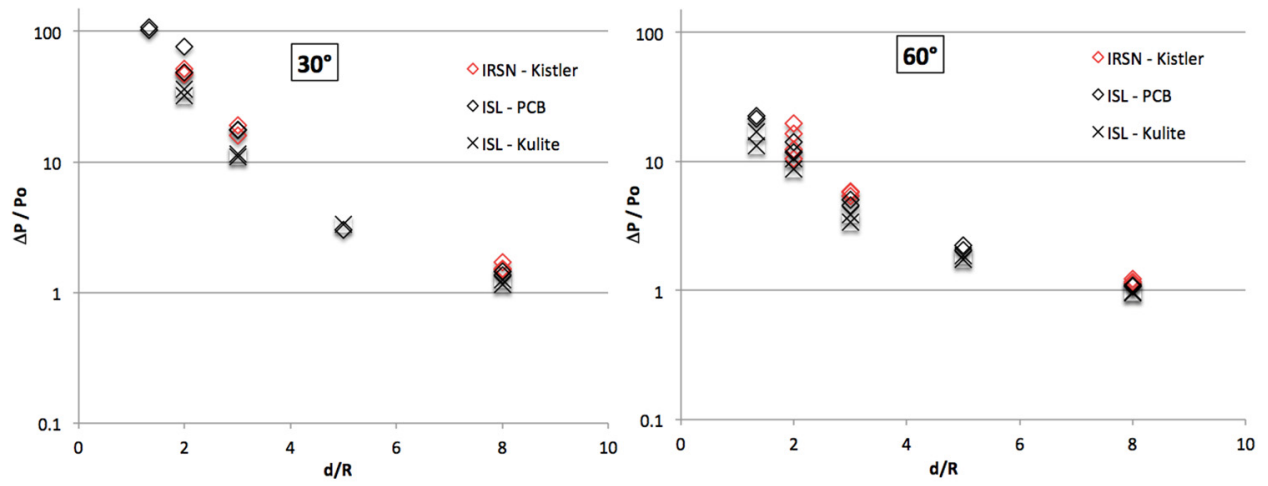

Figure 14: Peak overpressures dispersion for both scales at 30 and $60^{\circ}$. 


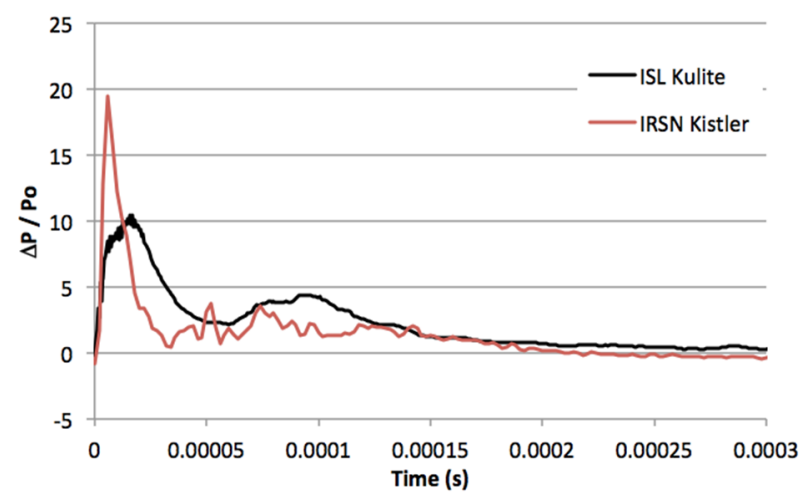

Figure 15: Comparison of overpressure evolutions at $\left(60^{\circ} / 0.4 \mathrm{~m}\right)-$ ISL Kulite versus IRSN Kistler.

\section{CONCLUSION AND PERSPECTIVES}

Blast wave interaction with a convex structure was investigated by IRSN and ISL through a twin reduced scale experimental approach. The effects of hemispherical Hexomax ${ }^{\circledR}$ charges were characterized in free-field and at the surface of a hemi-cylindrical obstacle. Based on the $42 \mathrm{~g}$ charge (50 g TNT equivalent) configuration defined in previous IRSN work, ISL designed a factor 2 up-scaled setup by using 333 g Hexomax ${ }^{\circledR}$ hemispheres (400 g TNT equivalent). Blast wave propagation was examined through the peak overpressures recorded with different types of pressure sensors placed on the blast pad and the target surface: piezoelectric (Kistler at IRSN, PCB at ISL) and piezo-resistive (Kulite at both scales).

Free-field tests demonstrated a good agreement between the different measurements for scaled distances further than $2 \mathrm{~m} / \mathrm{kg}^{1 / 3}$. In closer range, the discrepancy between piezoelectric and piezo-resistive sensor peak overpressures reached up to $40 \%$ due to the proximity to the charge (thermal effect, high pressure induced oscillation, rise time differences, etc.). These discrepancies could however be partially mitigated by using the classic method based on exponential correlation described in literature.

Influence of charge distance and sensor technology on the leading shock was also assessed on the front face of the hemi-cylinder ( 30 and $60^{\circ}$ angular positions). For $90^{\circ}, 120^{\circ}$ and $150^{\circ}$, the wave expansion progressively mitigates the initial pressure rise, leading to non-standard type of blast wave profile. As in free-field, convergence of peak overpressure measurements was observed for further distances between the charge and the obstacle whereas discrepancy between the piezo-electric and piezo-resistive responses could excess $60 \%$ in very close range $(\mathrm{d} / \mathrm{R}<2)$.

These results will provide guidelines for designing reduced scale experiments in order not to under or overestimate pressure effects, which could lead to a misprediction of the full size target survivability.

\section{REFERENCES}

[1] Cheval, K., Loiseau, O. \& Vala, V., Laboratory scale tests for the assessment of solid explosive blast effects. Part I: Free-field test campaign. Journal of Loss Prevention in the Process Industries, 23(5), pp. 613-621, 2010. 
[2] Cheval, K., Loiseau O. \& Vala V., Laboratory scale tests for the assessment of solid explosive blast effects, Part II: Reflected blast series of tests. Journal of Loss Prevention in the Process Industries, 25(3), pp. 436-442, 2012.

[3] Trélat, S., Impact de fortes explosions sur les bâtiments représentatifs d'une installation industrielle. PhD thesis, Université d'Orléans, 2006.

[4] Sochet, I., Blast Effects, Springer, 2018.

[5] Trélat, S., Sturtzer, M.-O. \& Eckenfels, D., Multi-scale experimental study of blast propagation around a hemi-cylindrical barrier, submitted to the 16th International Conference on Structures under Shock and Impact, Lisbon, Portugal, 22-24 Jun. 2020.

[6] Glasstone, S. \& Dolan, P.J., The Effects of Nuclear Weapons, 3rd ed., US Departments of Defense and Energy: Washington, DC, 1977.

[7] Kinney, G.F. \& Graham, K.J., Explosive Shocks in Air, Springer Verlag, 1985.

[8] Ethridge, N.H., A Procedure for reading and smoothing pressure-time data From HE and nuclear explosions. Ballistic Research Laboratories Memorandum Report No. 1691, 1965.

[9] Fourmann, J., Système sans fil de mesure ultra-rapide de la surpression aérienne en environnement extrême. PhD thesis, Université de Toulouse, 2017. 